\title{
PENGARUH SISTEM OLAH TANAH DAN APLIKASI MULSA BAGAS TERHADAP INFILTRASI PADA PERTANAMAN TEBU (Saccharum officinarum L.) RATOON KEDUA
}

\author{
Setiawan Aripin ${ }^{1}$, Irwan Sukri Banuwa ${ }^{2}, \&$ Ainin Niswati ${ }^{2}$ \\ Jurusan Agroteknologi, Fakultas Pertanian Universitas Lampung, \\ J1. Prof. SoemantriBrodjonegoro, No. 1, Bandar Lampung 35145. \\ Email : Setiawanarifin91@gmail.com
}

\begin{abstract}
ABSTRAK
Penelitian ini bertujuan untuk mempelajari pengaruh sistem pengolahan tanah dan pemberian mulsa bagas terhadap laju infiltrasi pada lahan pertanaman tebu (Saccharum officinarum L.) ratoon kedua. Penelitian ini dilaksanakan dari bulan Juni 2013 sampai pada bulan September 2013 dan pengamatan infiltrasi dilakukan pada bulan Juni 2013 (selesai panen tebu) di PT GMP, Lampung Tengah. Penelitian ini merupakan penelitian pada musim tanam ke 3 (ratoon kedua), Pengukuran infiltrasi langsung dilakukan dilahan PT GMP dan analisis contoh tanah dilakukan di Laboratorium Ilmu Tanah, Jurusan AGT, Fakultas Pertanian, Universitas Lampung untuk mengetahui sifat fisik tanah. Perlakuan disusun dalam rancangan petak terpisah (split plot design) dalam rancangan acak kelompok (RAK) dengan 5 kali ulangan. Petak utama yaitu sistem olah tanah, yang terdiri dari OTI $\left(\mathrm{T}_{1}\right)$ dan TOT $\left(\mathrm{T}_{0}\right)$. Anak petak adalah aplikasi mulsa bagas, yang terdiri dari mulsa bagas $80 \mathrm{t} \mathrm{ha}^{-1}\left(\mathrm{M}_{1}\right)$ dan tanpa mulsa bagas $80 \mathrm{t} \mathrm{ha}^{-1}\left(\mathrm{M}_{0}\right)$. Dengan demikian terbentuk 4 kombinasi perlakuan dengan 5 kelompok sehingga diperoleh 20 satuan percobaan. Adapun kombinasi perlakuan yang diterapkan adalah sebagai berikut: $\mathrm{T}_{1} \mathrm{M}_{1}=$ olah tanah intensif + mulsa bagas $80 \mathrm{tha}^{-1} ; \mathrm{T}_{1} \mathrm{M}_{0}=$ olah tanah intensif + tanpa mulsa bagas; $\mathrm{T}_{0} \mathrm{M}_{1}=$ tanpa olah tanah + mulsa bagas $80 \mathrm{t} \mathrm{ha}^{-1} ; \mathrm{T}_{0} \mathrm{M}_{0}=$ tanpa olah tanah + tanpa mulsa bagas; Data total infiltrasi yang diperoleh dianalisis dengan sidik ragam pada taraf $1 \%$ dan 5\%, yang sebelumnya diuji homogenitas ragamnya dengan Uji Bartlett dan aditivitasnya dengan Uji Tukey. Rata-rata nilai tengah diuji dengan uji Beda Nyata Terkecil (BNT) pada taraf 1\% dan 5\%. Dibuat kurva laju infiltrasi. Hasil penelitian menunjukkan bahwa : (1) Kapasitas dan kecepatan laju infiltrasi pada sistem OTI lebih tinggi dibandingkan dengan sistem TOT; (2) Perlakuan sistem OTI maupun TOT dengan aplikasi mulsa bagas $80 \mathrm{t} \mathrm{ha}^{-1}$ tidak berpengaruh terhadap meningkatnya laju infiltrasi; (3) tidak terdapat interaksi antara sistem olah tanah dengan aplikasi mulsa bagas terhadap laju infiltrasi tanah.
\end{abstract}

Kata kunci : infiltrasi, mulsa bagas, sifat fisik tanah.

\section{PENDAHULUAN}

Tanaman tebu (Saccharum officinarum L.) merupakan salah satu komoditas penting untuk dijadikan bahan utama pembuatan gula yang sudah menjadi kebutuhan primer dalam rumah tangga, hal ini karena dalam batangnya terkandung $20 \%$ cairan gula. Sebagian besar tanaman tebu ditanam pada tanah ultisol. Tanah ultisol umumnya telah mengalami pelapukan lanjut. (Prasetyo dan Suriadikarta, 2006). Oleh karena itu, berbagai usaha dilakukan untuk memperbaiki tanah ini.

Pemberian bahan organik pada tanah dapat menurunkan bulk density tanah, hal ini disebabkan karena bahan organik yang ditambahkan mempunyai kerapatan jenis yang lebih rendah. Kepadatan tanah erat hubungannya dengan penetrasi akar dan produksi tanaman. Jika terjadi pemadatan tanah maka air sulit disimpan dan ketersediaannya terbatas dalam tanah, sehingga menyebabkan terhambatnya pernapasan akar dan penyerapan air serta mengakibatkan proses infiltrasi terganggu (Hakim, dkk., 1986).

Turunnya produksi tanaman tebu disebabkan oleh kultur teknis yang tidak tepat, salah satunya adalah penggunaan alat berat. Pemadatan tanah terjadi akibat penggunaan traktor dan peralatan mekanis yang intensif. Penggunaan alat berat ini akan memberikan dampak negatif berupa terjadinya perubahan sifat fisik dan mekanik tanah seperti pemadatan tanah sehingga infiltrasi terganggu yang akan menyebabkan menurunnya pertumbuhan vegetatif tanaman yang akhirnya akan menurunkan produksi tanaman (Burdiono, 2012).

Penerapan kaidah konservasi tanah diperlukan untuk mengembalikan fungsi tanah-tanah yang rusak kemudian merehabilitasi tanah-tanah yang rusak secara lestari sehingga apabila ditanami kembali diharapkan akan mendapatkan produksi yang baik (Hardjowigeno, 1995). Penelitian ini bertujuan untuk mempelajari 
pengaruh sistem pengolahan tanah dan pemberian mulsa bagas terhadap laju infiltrasi pada lahan pertanaman tebu (Saccharum officinarum L.) ratoon kedua.

\section{METODE PENELITIAN}

Penelitian ini dilaksanakan pada bulan Juni 2013 sampai pada bulan September 2013 dan pengamatan infiltrasi dilakukan pada bulan Juni 2013 (selesai panen tebu) ratoon 2. Penelitian ini dilakukan di lahan pertanaman tebu (Saccharum officinarium L) di PT GMP, Lampung Tengah. Penelitian ini merupakan penelitian pada musim tanam ke 3 (ratoon kedua). Jenis tanaman tebu yang digunakan adalah varietas RGM 00838. Pengukuran infiltrasi langsung dilakukan di lahan PT GMP dan analisis contoh tanah dilakukan di Laboratorium Ilmu Tanah, Jurusan AGT, Fakultas Pertanian, Universitas Lampung untuk mengetahui sifat fisik tanah. Alat-alat yang digunakan dalam penelitian ini diantaranya adalah sekop, cangkul, gayung, kayu/ papan, palu karet, ember, drum, penggaris, plastik, meteran, stop watch, ring sampel (untuk mengambil contoh tanah dalam menentukan bulk density, oven, timbangan elektrik, double ring infiltrometer (untuk pengukuran laju infiltrasi tanah). Bahan yang digunakan adalah limbah padat pabrik gula yaitu ampas tebu (bagas), pupuk Urea, pupuk TSP, pupuk MOP sampel tanah untuk penetapan kadar air dan ruang pori tanah, kerapatan isi, dan air untuk mengukur laju infiltrasi.

Perlakuan disusun dalam rancangan petak terpisah (split plot design) dalam rancangan acak kelompok (RAK) dengan 5 kali ulangan. Petak utama yaitu sistem olah tanah, yang terdiri dari OTI $\left(\mathrm{T}_{1}\right)$ dan TOT $\left(\mathrm{T}_{0}\right)$. Anak petak adalah aplikasi mulsa bagas, yang terdiri dari mulsa bagas $80 \mathrm{t} \mathrm{ha}^{-1}\left(\mathrm{M}_{1}\right)$ dan tanpa mulsa bagas $80 \mathrm{t} \mathrm{ha}^{-1}\left(\mathrm{M}_{0}\right)$. Dengan demikian terbentuk 4 kombinasi perlakuan dengan 5 kelompok sehingga diperoleh 20 satuan percobaan. Adapun kombinasi perlakuan yang diterapkan adalah sebagai berikut:

$\mathrm{T}_{1} \mathrm{M}_{1}=$ olah tanah intensif + mulsa bagas $80 \mathrm{tha}^{-1}$ $\mathrm{T}_{1} \mathrm{M}_{0}=$ olah tanah intensif + tanpa mulsa bagas $\mathrm{T}_{0} \mathrm{M}_{1}=$ tanpa olah tanah + mulsa bagas $80 \mathrm{tha}^{-1}$ $\mathrm{T}_{0} \mathrm{M}_{0}=$ tanpa olah tanah + tanpa mulsa bagas

Data total infiltrasi yang diperoleh dianalisis dengan sidik ragam pada taraf $1 \%$ dan $5 \%$, yang sebelumnya diuji homogenitas ragamnya dengan Uji Bartlett dan aditivitasnya dengan Uji Tukey. Rata-rata nilai tengah diuji dengan uji Beda Nyata Terkecil (BNT) pada taraf $1 \%$ dan 5\%. Dibuat kurva laju infiltrasi.
Penelitian ini merupakan penelitian pada musim tanam ke 3 (ratoon kedua) pada tahun 2013. Jenis tanaman tebu yang digunakan adalah varietas RGM 00838. Lahan pada percobaan ini dibagi menjadi 20 petak percobaan sesuai dengan perlakuan dan ukuran tiap petak $25 \mathrm{~m}$ x $40 \mathrm{~m}$. Pemberian pupuk sesuai dengan dosis yang biasa diaplikasikan di PT GMP yaitu Urea $300 \mathrm{~kg} \mathrm{ha}^{-1}$, TSP (Triple Super Phospat) $200 \mathrm{~kg} \mathrm{ha}^{-1}$ dan MOP (Muriate of Potast) $300 \mathrm{~kg} \mathrm{ha}^{-1}$ diaplikasikan pada semua plot. Mulsa bagas diaplikasikan setelah penanaman tebu dengan dosis 80 tha $^{-1}$ untuk petak yang menggunakan mulsa bagas. Pada petak OTI, tanah diolah sesuai dengan sistem pengolahan tanah yang diterapkan di PT GMP yaitu sebanyak 3 kali pengolahan.

Penentuan lokasi pengambilan contoh tanah yang diamati dilakukan sebelum melakukan pemasangan alat double ring infiltrometer. Pengambilan contoh tanah disekitar tabung infiltrometer diambil pada kedalaman 0-20 $\mathrm{cm}$ dengan menggunakan ring sample dan kemudian contoh tanah dimasukkan ke dalam kantong plastik.

Analisis tanah pendukung dianalisis di Laboratorium Ilmu Tanah, Jurusan AGT, Fakultas pertanian, Universitas Lampung, Bandar Lampung, yang meliputi kadar air tanah, ruang pori tanah total dan kerapatan isi.

\section{Pelaksanaan Penelitian}

Pengelolaan Lahan. Penelitian ini merupakan penelitian jangka panjang yang berlangsung selama 10 tahun, dimulai pada tahun 2010 sampai dengan 2020. Penelitian ini merupakan penelitian pada musim tanam ke 3. Jenis tanaman tebu yang digunakan adalah varietas RGM 00-838. Lahan pada percobaan ini dibagi menjadi 20 petak percobaan sesuai dengan perlakuan dan ukuran tiap petak $25 \mathrm{~m}$ x $40 \mathrm{~m}$. Pemberian pupuk sesuai dengan dosis yang biasa diaplikasikan di PT GMP yaitu Urea $300 \mathrm{~kg} \mathrm{ha}^{-1}$, TSP (Triple Super Phospat) 200 $\mathrm{kg} \mathrm{ha}^{-1}$ dan MOP (Muriate of Potast) $300 \mathrm{~kg} \mathrm{ha}^{-1}$ diaplikasikan pada semua plot. Pada petak OTI, tanah diolah sesuai dengan sistem pengolahan tanah yang diterapkan di PT GMP yaitu sebanyak 3 kali pengolahan, yaitu: olah tanah I, olah tanah II dan olah tanah III.

Pengolahan tanah dilakukan pada lahan bekas tanaman tebu yaitu bertujuan untuk memecah tunggul tebu. Mulsa bagas diaplikasikan dengan cara ditebar dipermukaan tanah dengan dosis $80 \mathrm{t} \mathrm{ha}^{-1}$ bersamaan pada petak OTI. Mulsa BBA diaplikasikan setelah penanaman tebu dengan dosis $80 \mathrm{t} \mathrm{ha}^{-1}$. Sama seperti petak OTI, pada petak TOT dikendalikan secara manual dan sisa tumbuhan gulma dikembalikan ke lahan sebagai mulsa. 
Pengambilan Contoh Tanah. Penentuan lokasi pengambilan contoh tanah yang diamati dilakukan sebelum melakukan pemasangan alat double ring infiltrometer. Pengambilan contoh tanah disekitar tabung infiltrometer diambil pada kedalaman 0-20 cm dengan menggunakan ring sample.

Analisis Tanah. Analisis tanah pendukung dianalisis di Laboratorium Ilmu Tanah, Jurusan AGT, Fakultas pertanian, Universitas Lampung, Bandar Lampung, yang meliputi kadar air tanah, ruang pori tanah total dan kerapatan isi.

Pengamatan Infiltrasi Tanah. Menghitung laju infiltrasi menggunakan double ring infiltrometer (1) Ring pengukur dibenamkan secara vertikal ke dalam tanah sedalam $10 \mathrm{~cm}$ dan ring penyangga sedalam $5 \mathrm{~cm}$ menggunakan balok kayu. Setelah dibenamkan maka kedalaman ring cukup untuk membuat ring kuat berdiri, diameter ring yang digunakan $30 \mathrm{~cm}$. Pada double ring infiltrometer yang digunakan, maka ring pengukur dibenamkan terlebih dahulu sebelum ring penyangga. Perekatan dengan menggunakan liat dilakukan untuk menghindari kebocoran disekitar dinding ring. (2) Ring pengukur digenangi dengan tingkat kedalaman yang konstan, dan diukur kecepatan masuknya air ke dalam tanah pada ring pengukur (Gambar 1). (3) Tinggi genangan berkisar antara $10 \mathrm{~cm}$. Cara yang paling sederhana adalah dengan menambahkan air secara manual. Untuk mengetahui kapan air harus ditambahkan, diperlukan penunjuk/pointer (yang paling sederhana adalah penggaris). Ketika permukaan air dalam ring pengukur turun dan sampai pada titik penunjuk (pointer), maka dilakukan penambahan air sampai permukaan air dalam ring kembali ketitik awal. Rata-rata laju infiltrasi dihitung dari volume penambahan air dan interval waktu penambahan.

Aliran air yang konstan diasumsikan terjadi ketika kecepatan penurunan air di dalam ring menjadi konstan, dilihat dari perhitungan waktu dan penurunan air pada ring tidak mengalami perubahan atau penurunan lagi.

Analisis Data. Analisis data yang digunakan setelah data hasil pengukuran dengan menggunakan double ring infiltrometer (infiltrometer dua cincin) dalam penentuan laju infiltrasi yaitu menggunakan Model Persamaan Philip:

$$
\frac{\partial I}{\partial t}=i=\frac{1}{2} S t^{-1 / 2}+A
$$

Keterangan:

$\mathrm{i} \quad=$ Laju infiltrasi

$\mathrm{S}=$ Sorpsivitas $\left(\mathrm{mm} \mathrm{jam}^{-1 / 2}\right)$

$\mathrm{t} \quad=$ Akumulasi waktu (menit)

A $=$ Transmisivitas $\left(\mathrm{mm} \mathrm{jam}^{-1}\right)$ (Philip, 1975 dalam Mbagwu, 1997).

Di introduksikan ke program CurveExpert 1.3 untuk mempermudah perhitungan nilai Sorpsivitas dan Transmisivitas. Sedangkan borang pengisian laju infiltrasi mengikuti tata cara FAO (1987).

Variabel utama dalam penelitian ini adalah perhitungan laju infiltrasi air pada empat perlakuan sistem olah tanah yang ditanami tebu dengan menggunakan alat double ring infiltrometer.

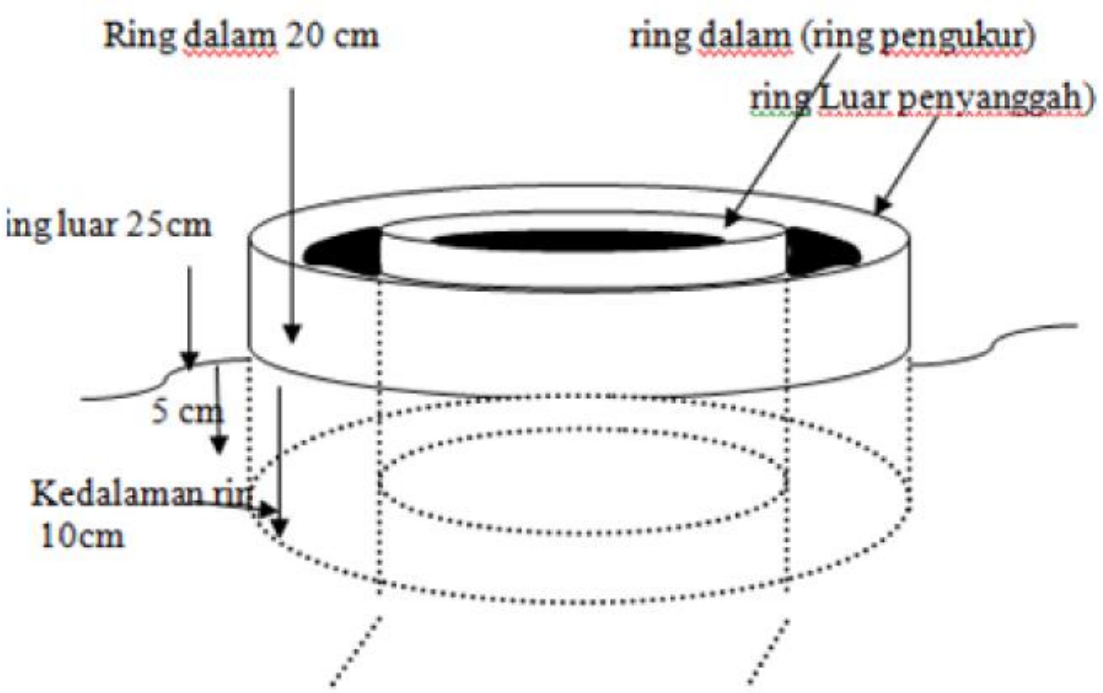

Gambar 1. Cara Kerja Alat Double Ring Infiltrometer 

ini yaitu:

Variabel pendukung yang diamati dalam penelitian

a. Bulk density (kerapatan isi) $\left(\mathrm{g} \mathrm{cc}^{-1}\right)$

b. Kadar air (\%)

c. Ruang pori tanah (\%)

d. Struktur tanah dengan metode lapang.

\section{HASIL DAN PEMBAHASAN}

Hasil analisis ragam menunjukkan bahwa sistem olah tanah memberikan pengaruh yang signifikan terhadap infiltrasi tanah, tetapi pemberian mulsa bagas tidak menunjukkan pengaruh yang signifikan terhadap infiltrasi tanah setelah 3 tahun perlakuan. Ragam kelompok pada sistem olah tanah dan aplikasi mulsa bagas tidak memberikan pengaruh yang signifikan terhadap infiltrasi tanah. Hal ini dapat kita lihat pada Tabel 1.

Tabel 1 menunjukkan bahwa perlakuan sistem olah tanah berpengaruh nyata terhadap laju infiltrasi dan aplikasi mulsa bagas tidak berpengaruh nyata terhadap laju infiltrasi tanah setelah perlakuan. Hal ini diduga karena pengaruh sistem olah tanah akan menyebabkan tanah menjadi lebih gembur dan ruang pori tanah lebih terbuka sehingga laju infiltrasi tanah akan menjadi lebih cepat. Aplikasi mulsa bagas tidak berpengaruh nyata dimungkinkan bahwa mulsa yang diaplikasikan pada lahan tersebut belum terdekomposisi secara sempurna dan tererosi pada saat hujan sehingga tanah pada lahan tersebut tidak gembur dan ruang pori serta struktur tanah yang kurang mantap menyebabkan pengaruh pemberian aplikasi mulsa bagas tidak berpengaruh nyata. Bentuk struktur tanah yang membulat (granular dan remah) menghasilkan tanah dengan daya serap tinggi sehingga air mudah meresap ke dalam tanah. Namun tanah berstruktur granular sangat mudah hancur oleh pukulan air hujan menjadi butir-butir halus, sehingga menutupi pori-pori tanah. Akibatnya infiltrasi tanah terhambat dan aliran permukaan (run off) meningkat (Afandi, 2004).

Hasil analisis ragam kumulatif infiltrasi dapat dilihat pada Tabel 1. Menunjukkan bahwa perlakuan sistem olah tanah berpengaruh nyata terhadap kumulatif infiltrasi tanah dan aplikasi mulsa bagas tidak berpengaruh nyata terhadap kumulatif infiltrasi tanah setelah perlakuan 3 tahun, serta terdapat interaksi antara sistem olah tanah dan aplikasi mulsa bagas terhadap kumulatif infiltrasi tanah.

Hasil analisis ragam Tabel 1. Menunjukkan bahwa perlakuan sistem olah tanah berpengaruh nyata terhadap kumulatif infiltrasi tanah. Hal ini dimungkinkan bahwa pengolahan tanah dapat mempercepat kumulatif laju infiltrasi tanah pada sistem olah tanah intensif dengan aplikasi mulsa bagas 80 tha $^{-1}$ dibandingkan dengan sistem tanpa olah tanah. Hal ini sejalan dengan penelitian Adhisaputra (2012), yang melaporkan bahwa campur tangan manusia dalam penerapan sistem olah tanah sangat mempengaruhi kumulatif laju infiltrasi sehingga dapat diartikan bahwa pengolahan tanah dapat meningkatkan kumulatif infiltrasi tanah.

Pengaruh sistem olah tanah dan pemberian mulsa bagas akan mempengaruhi sifat-sifat tanah, terutama sifat fisika tanah. Perbedaan perlakuan sistem olah tanah dan pemberian aplikasi mulsa bagas akan memberikan kondisi linkungan yang berbeda-beda untuk laju infiltrasi tanah (Tabel 2-6).

Hasil pengamatan pada pada Gambar 2. Menunjukkan bahwa perlakuan sistem olah tanah dan aplikasi mulsa bagas mempunyai perbedaan laju infiltrasi tanah yang berbeda pada setiap perlakuan sistem olah tanah. Pada perlakuan sistem olah tanah, sistem OTI mempunyai laju infiltrasi sebesar $366 \mathrm{~mm} \mathrm{jam}^{-1}$, sistem TOT mempunyai laju infiltrasi sebesar $288 \mathrm{~mm} \mathrm{jam}^{-1}$, dan pada perlakuan sistem olah tanah aplikasi mulsa bagas untuk sistem OTI aplikasi mulsa bagas $80 \mathrm{t} \mathrm{ha}^{-1}$ laju infiltrasi sebesar $432 \mathrm{~mm} \mathrm{jam}^{-1}$, sedangkan pada sistem TOT aplikasi mulsa bagas 80 tha $^{-1}$, laju infiltrasi tanah sebesar $324 \mathrm{~mm} \mathrm{jam}^{-1}$.

Gambar 2. Memperlihatkan bahwa adanya perbedaan infiltrasi tanah pada sistem olah tanah. Kecepatan laju infiltrasi pada sistem OTI + mulsa bagas $80 \mathrm{t} \mathrm{ha}^{-1}$ sebesar $432 \mathrm{~mm} \mathrm{jam}^{-1}$ (sangat cepat) sedangkan kecepatan laju infiltrasi tanah pada sistem TOT + mulsa

Tabel 1. Ringkasan analisis ragam pengaruh sistem olah tanah dan aplikasi mulsa bagas terhadap infiltrasi tanah dan kumulatif infiltrasi setelah perlakuan 3 tahun

\begin{tabular}{lcc}
\hline \multicolumn{1}{c}{ SK } & Infiltrasi & Kumulatif Infiltrasi \\
\hline Kelompok & tn & tn \\
Sistem Olah Tanah (T) & $*$ & $*$ \\
Aplikasi Mulsa $(\mathrm{M})$ & tn & tn \\
Interaksi & tn & $*$ \\
\hline
\end{tabular}

Keterangan $: \mathrm{T}=$ petak utama, $\mathrm{M}=$ anak petak, $\mathrm{tn}=$ tidak berbeda nyata, $*=$ berbeda nyata pada taraf $5 \%$. 
Tabel 2. Uji BNT pengaruh sistem olah tanah dan aplikasi mulsa bagas $80 \mathrm{t} \mathrm{ha}^{-1}$ terhadap infiltrasi tanah pada ratoon 2

\begin{tabular}{cc}
\hline Perlakuan & Infiltrasi tanah $\left(\mathrm{mm} \mathrm{jam}^{-1}\right)$ \\
\hline Olah tanah intensif & $432 \mathrm{a}$ \\
Tanpa olah tanah & $228 \mathrm{~b}$ \\
\hline $\mathrm{BNT}_{0.05}=56,84$ & \\
\hline
\end{tabular}

Keterangan: Angka yang diikuti oleh huruf yang tidak sama berbeda nyata menurut Uji BNT taraf nyata 5\%.

Tabel 3. Uji BNT pengaruh sistem olah tanah dan aplikasi mulsa bagas $80 \mathrm{t} \mathrm{ha}^{-1}$ terhadap kumulatif infiltrasi tanah $\left(\mathrm{mm} \mathrm{jam}^{-1}\right)$ setelah perlakuan

\begin{tabular}{ccc}
\hline Perlakuan & Mulsa bagas & Tanpa mulsa bagas \\
\hline OTI & $227.2 \mathrm{a}$ & $204.4 \mathrm{a}$ \\
& $\mathrm{A}$ & $\mathrm{A}$ \\
TOT & $203 \mathrm{ab}$ & $201 \mathrm{~b}$ \\
& $\mathrm{~B}$ & $\mathrm{~A}$ \\
\hline
\end{tabular}

$\mathrm{BNT}_{0.05}=21.03$

Keterangan: OTI = Olah tanah intensif; TOT= Tanpa olah tanah; Angka yang diikuti oleh huruf yang sama tidak berbeda nyata menurut Uji BNT taraf nyata $5 \%$. Huruf kecil dibaca mendatar dan huruf besar dibaca menurun.

Tabel 4. UJI BNT pengaruh sistem olah tanah dan aplikasi mulsa bagas terhadap kadar air tanah (\%)

\begin{tabular}{ccc}
\hline Perlakuan & Mulsa bagas & Tanpa mulsa bagas \\
\hline OTI & 20,06 a & 19,21 a \\
TOT & B & B \\
& 23,19 a & 22,74 a \\
\hline BNT $0,05=3,03$ & A & A
\end{tabular}

Keterangan: OTI = Olah tanah intensif; TOT= Tanpa olah tanah; Angka yang diikuti oleh huruf yang sama tidak berbeda nyata menurut Uji BNT taraf nyata 5\%. Huruf kecil dibaca mendatar dan huruf besar dibaca menurun.

Tabel 5. UJI BNT pengaruh sistem olah tanah dan aplikasi mulsa bagas terhadap Kerapatan isi $\left(\mathrm{g} \mathrm{cm}^{-3}\right)$

\begin{tabular}{cc}
\hline Perlakuan & Kerapatan isi $\left(\mathrm{g} \mathrm{cm}^{-3}\right)$ \\
\hline Olah tanah intensif & $1,40 \mathrm{~b}$ \\
Tanpa olah tanah & $1,44 \mathrm{a}$ \\
BNT $0,05=0,03$ & \\
\hline
\end{tabular}

Keterangan: Angka yang diikuti oleh huruf yang tidak sama berbeda nyata menurut Uji BNT taraf nyata $5 \%$.

Tabel 6. UJI BNT pengaruh sistem olah tanah dan aplikasi mulsa bagas terhadap ruang pori (\%)

\begin{tabular}{cc}
\hline Perlakuan & Ruang pori (\%) \\
\hline Olah tanah intensif & $46,96 \mathrm{~b}$ \\
Tanpa olah tanah & $49,45 \mathrm{a}$ \\
BNT 0,05 =0,65 & \\
\hline
\end{tabular}

Keterangan : Angka yang diikuti oleh huruf yang sama tidak berbeda nyata menurut Uji BNT taraf 5\%. 


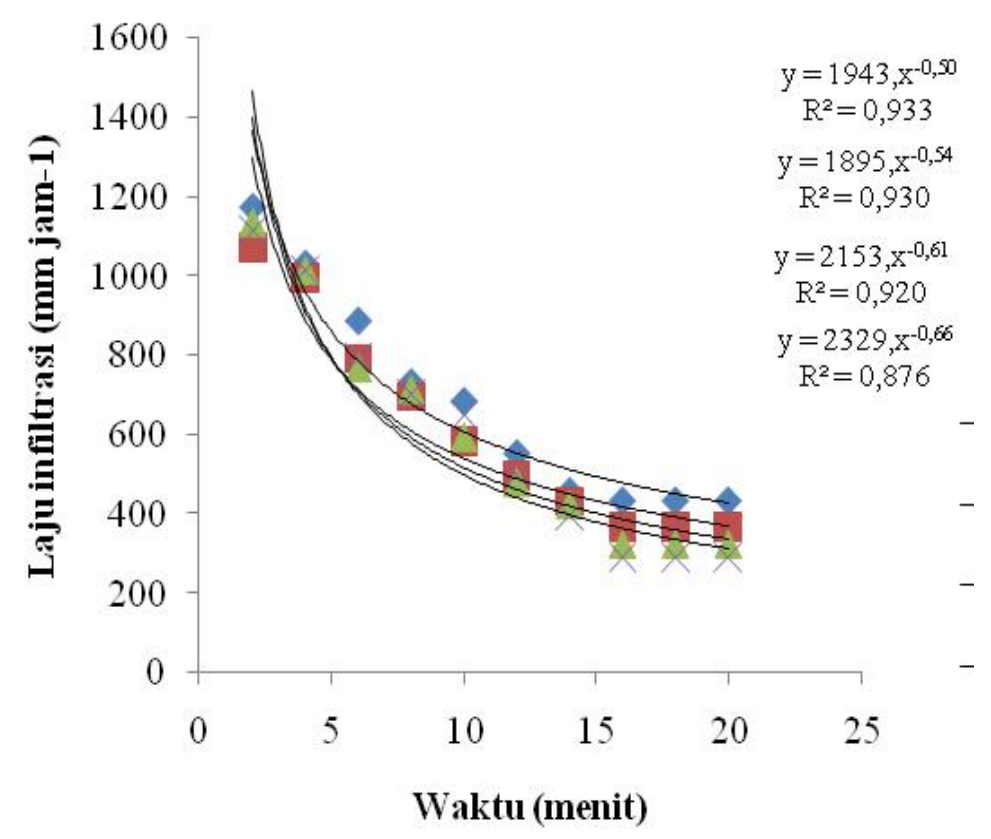

Gambar 2. Kurva laju infiltrasi tanah pada sistem olah tanah dengan dan tanpa aplikasi mulsa bagas Kererangan: $\diamond=$ (T1) Sistem OTI + Mulsa Bagas $80 \mathrm{t} \mathrm{ha}^{-1}$ (M1), $\square=(\mathrm{T} 1)$ sistem OTI tanpa mulsa bagas $80 \mathrm{t} \mathrm{ha}^{-1}$ (M0), $\Delta=$ (T0) sistem TOT + Mulsa Bagas $80 \mathrm{t} \mathrm{ha}^{-1}$ (M1), $\tilde{W}=$ (TO) sistem TOT tanpa mulsa bagas $80 \mathrm{t} \mathrm{ha}^{-1}$ (M0)

Tabel 7. Data pengamatan stuktur tanah menggunakan metode lapang

\begin{tabular}{|c|c|c|c|}
\hline \multirow{2}{*}{ Perlakuan } & \multirow{2}{*}{ Lokasi } & \multicolumn{2}{|c|}{ Kedalaman } \\
\hline & & $(0-20 \mathrm{Cm})$ & $(20-50 \mathrm{Cm})$ \\
\hline \multirow{5}{*}{ TIMI } & A1 & Gumpal bersudut & Gumpal bersudut \\
\hline & $\mathrm{A} 2$ & Gumpal sub angular blocky & Gumpal sub angular blocky \\
\hline & A3 & Gumpal bersudut & Gumpal bersudut \\
\hline & A4 & Gumpal bersudut & Gumpal bersudut \\
\hline & A5 & Gumpal sub angular blocky & Gumpal sub angular blocky \\
\hline \multirow{5}{*}{ TIMO } & B1 & Gumpal sub angular blocky & Gumpal bersudut \\
\hline & B2 & Gumpal bersudut & Gumpal sub angular blocky \\
\hline & B3 & Gumpal bersudut & Gumpal sub angular blocky \\
\hline & B4 & Gumpal bersudut & Gumpal bersudut \\
\hline & B5 & Gumpal sub angular blocky & Gumpal sub angul ar blocky \\
\hline \multirow{5}{*}{ TOMO } & $\mathrm{C} 1$ & Gumpal sub angular blocky & Gumpal sub angular blocky \\
\hline & $\mathrm{C} 2$ & Gumpal sub angular blocky & Gumpal sub angular blocky \\
\hline & $\mathrm{C} 3$ & Gumpal sub angular blocky & Gumpal sub angular blocky \\
\hline & $\mathrm{C} 4$ & Gumpal sub angular blocky & Gumpal sub angular blocky \\
\hline & $\mathrm{C} 5$ & Gumpal bersudut & Gumpal bersudut \\
\hline \multirow{5}{*}{ TOMI } & D1 & Gumpal sub angular blocky & Gumpal sub angular blocky \\
\hline & D2 & Gumpal sub angular blocky & Gumpal bersudut \\
\hline & D3 & Gumpal sub angular blocky & Gumpal bersudut \\
\hline & D4 & Gumpal sub angular blocky & Gumpal bersudut \\
\hline & D5 & Gumpal sub angular blocky & Gumpal bersudut \\
\hline
\end{tabular}

Keterangan : TIMI : Olah tanah intensif + mulsa bagas, TIMO : Olah tanah intensif + tanpa mulsa, TOMO : Tanpa olah tanah + tanpa mulsa, TOMI : Tanpa olah tanah + mulsa bagas 
bagas sebesar $324 \mathrm{~mm} \mathrm{jam}^{-1}$ (lebih lambat) hal ini menunjukkan bahwa pemberian mulsa bagas diatas permukaan tanah merupakan tindakan pelestarian (konservasi) sebagai upaya menambah bahan organik dalam tanah dan mulsa juga mempunyai peranan penting yaitu menyerap air sehingga mulsa bagas mampu mempercepat laju infiltrasi ke dalam tanah.

Hasil pengamatan laju infiltrasi (Gambar 2) menunjukkan bahwa tidak terdapat interaksi antara sistem olah tanah dan aplikasi mulsa bagas terhadap infiltrasi tanah. Hal ini diduga karena tanah yang sangat gembur apabila terjadi hujan mudah tererosi dan hanyut akan menyumbat pori-pori tanah sehingga tanah menjadi lebih padat. Hal ini juga menunjukkan bahwa pada olah tanah intensif belum mampu melindungi tanah dari aliran permukaan dan bahaya erosi. Arsyad (2006), menambahkan bahwa pengaruh pengolahan tanah hanya bersifat sementara menggemburkan tanah, selanjutanya akan terjadi erosi dan penyumbatan pori-pori tanah akibat pengolahan tanah yang salah.

\section{KESIMPULAN}

Dari hasil dan penelitian dapat disimpulkan bahwa kapasitas dan laju infiltrasi pada sistem OTI lebih tinggi dibandingkan dengan sistem TOT. Perlakuan sistem OTI maupun TOT dengan aplikasi mulsa bagas $80 \mathrm{t}$ ha${ }^{1}$ tidak berpengaruh terhadap meningkatnya laju infiltrasi. Terdapat interaksi antara sistem olah tanah dengan aplikasi mulsa bagas terhadap laju infiltrasi tanah.

\section{DAFTAR PUSTAKA}

Adhisaputra.2012. Pengaruh Sistem Olah Tanah dan Aplikasi Mulsa Bagas Terhadap Infiltrasi Tanah Pada Pertanaman Tebu (Saccharum Officinarum L.) di PT Gunung Madu Plantations (GMP) Lampung Tengah.Skripsi.Universitas Lampung. Bandar Lampung. $92 \mathrm{hlm}$.

Arsyad, S. 2010. Konservasi Tanah dan Air. Penerbit IPB. Cetakan 2 - Edisi Kedua. Bogor. 472 hal.

Burdino, M. 2012.Pemanfaatan Serasah Tebu Sebagai Mulsa Terhadap Pemadatan Tanah Akibat Lintasan Roda Traktor Pada PG. Takalar. Skripsi.Universitas Hasanuddin. Makasar

Hakim, N.,M. Y. Nyakpa, A.M. Lubis, S.G. Nogroho, M.A. Diha, G.B. Hong, dan H.H. Bailey. 1986. Dasar-dasarIlmu Tanah. Universitas Lampung. Bandar Lampung. $487 \mathrm{hlm}$.

Hardjowigeno, S. 1993. Klasifikasi Tanah dan Pedogenesis. Edisi pertama. Penerbit Akademika Pressindo: Jakarta.

Prasetyo, B.H. dan D.A. Suriadikarta. 2006. Karakteristik, Potensi, dan Teknologi Pengelolaan Tanah Ultisol Untuk Pengembangan Pertanian Lahan Kering di Indonesia. Balai Penelitian Tanah. Bogor. 